\title{
Contesting authentic practice and ethical authority in adventure tourism
}

Journal of Sustainable Tourism

\begin{abstract}
This paper examines the discourses of authenticity and ethics used among adventure tourists regarding the use of the natural environment. In one case, full-time traveling rock climbers use their dedication to the sport and annual visits to the Red River Gorge as evidence for their authoritative voice on ethical climbing practice. While they identify the growing numbers of leisure climbers as a problem for sustainability, many also take up temporary employment as guides and are directly involved in the introduction of new climbers to the area. In another case, two groups of wilderness enthusiasts - "ADK 46ers" and "Summit Stewards" - lament the environmental and social impacts of other recreational users in the Adirondack Park. Despite being visitors themselves, Summit Stewards and 46ers use their sense of place and knowledge of Adirondack history and ecology to substantiate their authority as purveyors of ethical practice. In both cases, senses of responsibility are inspired by senses of place, but are articulated through notions of authenticity and used as justification for ethical authority. While validating their presence in these outdoor spaces, the use of such rhetoric also minimizes their own impacts yielding further tensions among user groups.
\end{abstract}

Keywords: adventure, authenticity, ethics, rhetoric, rock climbing, hiking

Rickly, J and Vidon E. 


\section{Introduction}

Much of the study of adventure tourism to date relates to notions of risk and danger (see Ewert, 1985; Ewert \& Hollenhorst, 1989; Priest, 1990, 1992; Hall, 1992), desire for challenge (see Ewert, 1985; Csikszentmihalyi \& Selega, 1990; Rubens, 1999; Lewis, 2004), as the commodification of nature and wilderness (see Johnson \& Edwards, 1994;

Cloke \& Perkins, 1998, 2002; Palmer, 2002; Braun, 2006; Varley, 2006; Fletcher, 2014), and environmental and economic sustainability of adventure practices (see Fennell \& Eagles, 1990; Swarbrooke, 2003; Costa \& Chalip, 2005; Davidson \& Stebbins, 2011). Underlying much of this work are notions of neoliberal rights to access the world's natural and wild places, at the right price. In other words, adventure tourism carries forward many neocolonialist practices as a predominantly Western tourist activity (Mowforth \& Munt, 2003). And while this can be observed from structural and even post-structural approaches that examine the marketing and commodification of adventure (see Sung, Morrison, \& O’Leary, 2000; Weber, 2001; Cloke \& Perkins, 1998, 2002; Kane \& Zinc, 2004; Varley, 2006; Fletcher, 2014; Vidon, 2016) and the motivations of adventure tourists (see Ewert, 1985; Christensen, 1990; Csikszentmihalyi \& Selega, 1990; Ewert, 1993; Beedie, 2003; Kane \& Tucker, 2004), what has not been presented are existential and humanistic perspectives on the ethical dilemmas of these same adventure tourists. As this paper will discuss, many adventure tourists recognize the duplicitous nature of their pursuit - that it is both the result of privilege, and therefore requires a particular responsibility, but many also feel that access should be limited and controlled (primarily for others). To say that some individuals are selfish is too easy a 
conclusion. Instead, this paper seeks to examine adventure tourists through the concept of authenticity so as to illustrate their complexity as human beings who struggle, as we all do, with sometimes dissonant tendencies to rationalize simultaneous yet opposing "truths". Authenticity is a concept that includes perceptions and experiential qualities related to place, practice, identity, and intersubjective relationships (Wang, 1999; RicklyBoyd, 2013). As Senda-Cook (2012) explains, authenticity is a rhetorical practice that extends beyond semantics to the embodied practices of outdoor recreation. We investigate the way authenticity is used by adventure tourists to rationalize sense of place, ethical authority, and identity politics.

As a category that includes adventure tourism and recreation, Davidson and Stebbins (2011, p. xi) suggest "nature challenge enthusiasts [...] often make fine champions of sustainability and the consumption of goods and services enabling the activity while causing minimal environmental damage". Without intent to discredit their observation, we challenge the means by which "minimal environmental damage" is accomplished, who is excluded, and who claims ethical authority in championing sustainability. Sustainability is not a neutral concept and cannot be considered in isolation from its sociopolitical context (Cohen, 2002, p. 268). Thus "just sustainability" necessitates the examination of equity and fairness as well as value systems, ethical judgments, and relations of knowledge, power, and contestation that relate to social justice (Agyeman \& Evan, 2004; Bramwell \& Lane, 2008; Cohen, 2002). Responding to their call for attention to the "processes of valuation" - "how and why certain kinds of relative 'permanence' get constructed in particular places and times so as to form the dominant 
social values about equity” (Bramwell \& Lane, 2008, p. 3) - and Cohen's (2002)

assertion that discourses of authenticity permeate the politics of sustainability, we interrogate the use of authenticity and ethics rhetoric by adventure tourists to understand how they value the natural spaces of their respective activities and how they value other users of these spaces. It is, therefore, important to note that we are not arguing for a "correct" or "right" point of view in the cases presented here, nor do we side with the a single voice heard in the quotes below. Rather, we wish to shed light on the dissonance of rhetoric and practice within and between adventure tourist subcultures so as to illustrate the diversity of voices and values regarding authentic practice, responsible use, and ethical authority.

This is a comparative analysis of two tourism sites and the adventure tourists who are among the most vocal about issues of rights to access, responsibility of use, and sense of place. We argue that authenticity plays a significant role in these tourists' notions of ethical authority. We use the tourist typology "adventure tourists" broadly in order to capture the distinct subcultures in these two cases - rock climbers and wilderness enthusiasts. In one case, rock climbing in the Red River Gorge of Kentucky, USA, is approached from the view of lifestyle climbers - full-time, traveling rock climbers who frequent this region. For lifestyle climbers, access to climbing spaces is a political priority, and yet, many also express judgments as to which climbing subcultures should have access to these spaces and to what extent. They use their lifestyle commitment to rock climbing as leverage for a more ethical authoritarian voice, while at the same time recognizing the problems inherent in this rationality. As such, a moral struggle was 
observed among lifestyle climbers as they debate the authority and responsibility of fashioning and policing ethical climbing practices in the region. In a second case, wilderness enthusiasts ("Summit Stewards" and "ADK 46ers") of the Adirondack Park in Upstate New York exhibit similar ambivalences regarding their use of the Park. Summit Stewards are a group of mostly tourists and some local residents who reside within the Park during the summer tourism season. ADK 46ers are a subculture of hikers in the Park who have summited all of the peaks over 4,000 feet. While many maintain that these environs constitute their favorite playgrounds, they struggle with possible impacts from increased traffic on the mountains as a result of the site's popularity among hikers. Their considerable experience in the Park's High Peaks affords them a sense of authority and expertise that they often use to educate other hikers on wilderness etiquette and responsibility. At the same time, they struggle with competing identities as both mountain advocates/protectors and mountain users. In both cases, senses of responsibility are inspired by senses of place, which are articulated through notions of authenticity and used as justification for ethical authority. In validating their presence in these outdoor spaces, the use of authenticity rhetoric also minimizes their own impacts while pushing blame onto other users.

\section{Adventure tourism}

Adventure tourism is comprised of three primary components: travel, sport, and outdoor recreation (Beedie \& Hudson, 2003), with experiential factors including uncertainty 
(Priest, 1990), risk (Ewert, 1985; Hall, 1992), and challenge (Csikszentmihalyi \& Selega, 1990). Yet, the degree to which each of these aspects relates to adventure tourism remains debated. For example, Price (1978) contends that planning of outdoor recreation negates its "adventure" status, whereas Hall (1992) suggests that the activity is prioritized over the setting. Further, Christiansen (1990) examines the difference between soft (perceived risk with little actual risk) and hard adventure (high level of known risk) (see also Swarbrooke, 2003). Nevertheless, more recent research contends that adventure is individualistic and subjective, yet also distinct from other types of tourism, as Varley (2011, p. 86) states, "[t]here is something in the uncertainties and challenges that can serve to give all these tourists (expert-dependent 'post-adventurers' and independent 'original adventurers' alike) a particular bond which distinguishes them from other tourists" (see also, Beedie, 2008).

\section{Experiential factors and identity politics}

While uncertainty, risk, and challenge remain important experiential factors to adventure tourism, generally, individuals' motivations also extend to notions of self-identity and social capital. It has been suggested that as adventure participants gain experience in their outdoor recreational activities, their perceptions of competence increases, thereby reducing their perceptions of risk (see Ewert, 1993; Ewert \& Hollenhorst, 1989, 1994; Beedie \& Hudson, 2003). In particular, Ewert's (1985) research on climbers at Mount Ranier found that the experience level of individuals corresponded to differing sources of motivation. While inexperienced climbers noted recognition, escape, and social reasons as motivation, experienced climbers described more intrinsic reasons, specifically 
exhilaration, challenge, personal testing, decision-making, and locus of control. Thus, it is not surprising that these adventure tourism communities are riddled with internal divisions and subcultures related to style of use and ethics (see Williams \& Donnelly, 1985; Heywood, 1994; Kiewa, 2002; Wheaton, 2004, 2007) and that they compete over access to outdoor recreational resources (see, for example, Scott, 1994).

That adventure tourists' motivations relate as much to identity politics as they do intrinsic experience suggests the effectiveness of commodification of adventure and its accompanying natural spaces. In particular, Cloke and Perkins (2005) note that it is the contrast of adventure tourism to mass tourism that makes its marketing of thrill and natural spectacle especially effective. Indeed, their examination of adventure marketing in New Zealand suggests that in the commodification of nature and tourism, not only are tourists able to consume adventure, but place, culture, and the social capital of having visited those destinations are also made available for purchase. As Kane and Tucker (2004, p. 231) explain, adventure tourism is "a signifier of who you are, who you would

like to be and who you are not". This, Wheaton and Beal (2003) suggest, has implications for the perceptions of adventure advertising as action photos are associated with more "authentic" representations of the activity related to lifestyle engagement and therefore identity politics.

\section{Authenticity and adventure tourism}

Authenticity is a widely studied concept in tourism that can be approached from a number of theoretical perspectives: objectivism, constructivism, postmodernism, and 
existentialism (Wang, 1999). However, more recent research suggests that these perspectives are relational and performative (see Knudsen and Waade, 2010; SendaCook, 2012; Rickly-Boyd, 2012a). So while objective, constructive, and postmodern notions of authenticity are object-based (Wang, 1999), tourists' experiences and perceptions of these are enacted in the performance of tourism. Existential authenticity, however, is an activity-based approach that prioritizes authenticity as experiential, resulting from embodiment, identity, and intersubjectivity (Wang, 1999). These are more internally experienced factors; yet, the materiality of place is crucial to a more complete engagement with existential authenticity and its constituent factors (see Belhassen, Caton, \& Stewart, 2008; Senda-Cook, 2012; Rickly-Boyd, 2013).

The body is at the forefront of adventure experience in the form of embodied performances and deep emotional connections to place, such that uncertainty, challenge, and perceptions of risk are much more than cognitive interactions with landscape; they are in fact assessments of one's mental and bodily ability in particular settings (see Csikszentmihalyi \& Selega, 1990). Indeed, it is embodied experience that grounds those mental associations in a place. Whether rock climbing in The Red or hiking in the Adirondacks, it is the bodily experience - physical sensations of sunshine, rain, and wind, the texture of rock and trail, and the aches of muscles - that authenticate being in place (see Rickly-Boyd, 2012b; Vidon, 2015). It is through these embodied practices that place is performed, and through "appropriate" practice that authenticity is performed. In other words, the embodied nature of adventure influences one's perceptions of their experience as authentic, but the way individuals engage in this bodily practice is also assessed by 
fellow users. As Senda-Cook's (2012, p. 146) study of hikers in Zion National Park suggests, "practices that do not conform to outdoor recreation expectations challenge authenticity because those practices show the multiple ways of doing outdoor recreation". Thus, the embodied adventure experience is relational to experiences of place and has significant implications for notions of identity - individually and collectively. The physical and mental challenges of adventure that tests one's limits outside of everyday environs are crucial to "self-making" (Wang, 1999). In the case of adventure tourism, this has the effect of solidifying individuals' sense of self but also one's social relations, as such activities are frequently undertaken alongside others of similar interests and attitudes (see Varley, 2011; Rickly-Boyd, 2012b; Vidon, 2015). Through adventure tourism, intersubjective encounters extend beyond communitas, spontaneous, temporary communities (Wang, 1999), to stronger companionship relations by way of the heightened elements of risk, and therefore trust among adventurers. Adventure tourism offers moments of existential authenticity through challenges that emphasize bodily experience, sense of self, and companionship (see Varley, 2006, 2011; Rickly- Boyd, 2012b), but the embodied practice of adventure can also be used to assess fellow users (see Senda-Cook, 2012).

\section{Research sites and methods}

It is important to note that findings presented in this paper are the result of two studies that were compiled and executed independently by each author. It was only after each 
project was completed that discussion revealed similarities and a comparative analysis was conducted. So while each site was chosen with distinct research goals, both projects employed similar methodologies, as they were both interested in tourists' motivations and experiences in relation to perceptions of authenticity and the natural environment. Comparison of these independent studies suggested more generalizable findings regarding authenticity rhetoric and environmental ethics as exclusionary practices. In what follows, brief descriptions of each site and the respective methods are offered to provide context the comparative analysis. This is followed by a discussion of the comparative analysis.

\section{Lifestyle rock climbers in the Red River Gorge, Kentucky, USA}

The Red River Gorge in Appalachian Kentucky has become one of the world's premiere sport $^{1}$ climbing destinations in recent decades and its popularity only continues to grow as more climbing areas are accessed, routes developed, and exposés are featured in popular climbing media. While nature tourists and wilderness enthusiasts have been visiting this area for decades, rock climbers only began to include The Red in their circuits in the late 1980s when route development proliferated and the first guidebooks were published. Today, when visiting The Red, one finds a diverse community comprised of leisure climbers who engage with the sport recreationally as tourists, residential climbers who live in the region permanently, lifestyle climbers who self-fund their fulltime commitment to climbing and travel, and a few professional rock climbers who earn an income from their climbing through corporate sponsorships. 
This comparative analysis uses data collected through research on one subculture of the rock climbing community in this region - lifestyle climbers. These are individuals who have prioritized rock climbing, giving up sedentary housing and employment in order to travel and climb full-time, and thereby take up mobile, internet-based, and/or part-time employment along the way. Fieldwork in The Red took place during peak climbing season - August through November of 2011 - and included observation of the rock climbing community as a whole with semi-structured, in-depth interviews of lifestyle climbers, more specifically. A total of 21 interviews were conducted -6 females and 15 males - representing the gender disparity of the lifestyle climber population overall. The age of participants ranged from 22 to 56 years. Mobility varied and the time spent travelling for full-time climbing extended from just six months to 17 years. Interviewees were, as reflected in the rock climbing population in general, predominantly white (Erikson, 2005). All but two interviewees were Americans, with the exception of one Canadian and one person from France, and two respondents self-identified as gay and lesbian, respectively. Data collection also included discourse analysis of climbing media (magazines, films, forums, and websites/blogs).

\section{"Summit Stewards" and "46ers" of The Adirondack Park, New York, USA}

The Adirondack Park in Upstate New York is a nearly six million acre area known largely for its wilderness landscapes and the recreational opportunities therein. Created in 1892 amid concerns for the area's timber and water resources, the Park has been increasingly popular among tourists. It is a unique landscape comprised of both public (State) land and private land, and while most tourists prefer its less developed areas and 
the designated "wilderness" of the High Peaks, many also flock to the Park's communities and more built attractions.

Data for this examination were collected as part of a larger project on nature tourists in wilderness areas of the Adirondack Park. For the purposes of this research, nature tourists are defined as those individuals whose primary motivation for visiting the Park is to engage with the natural, nonhuman environment. Two subgroups of nature tourists were identified as "wilderness enthusiasts": "ADK 46ers" and "Summit Stewards". ADK 46ers are members of a club of hikers who have summited all 46 of the Adirondack's highest peaks (over 4,000 feet). Those who work as Summit Stewards constitute a small subculture who have chosen to work in the High Peaks region of the Park during the summer tourism season educating hikers on responsible use of the wilderness areas and how to protect the alpine vegetation on the Peaks. While some 46ers and Summit Stewards are Park residents, those indicated in this study are visitors and/or seasonal workers. Field research in the Adirondack Park was conducted from May through September of 2014 - the height of the tourism season. Data from this work are comprised primarily of in-depth interviews (43 total) with participants ranging in age from 19 to 77, with 24 females and 19 males. Further, discourse analysis was performed on Adirondack-related blogs, websites, and social media pages.

\section{Comparative analysis}

Following independent analysis of data collected at both research sites using HyperReseach and NVivo, respectively, strong, minority opinions regarding authenticity 
rhetoric and environmental ethics in relation to notions of authority, responsibility, and sustainability were revealed. In seeking out how best to test the generalizability of this smaller subset of data, the authors conducted a comparative analysis of the two sites by returning to the original interview data and media sources for a second round of analysis targeting the themes of ethics, etiquette, authority, responsibility, authentic practice, education, and subcultures. Among the findings were rather lengthy quotes and media passages that describe conflicting emotions and tension between user groups. In the section that follows, we have chosen to use fewer but lengthier quotes that demonstrate the emotional struggles and ethical dilemmas these participants expressed. The use of longer quotes is significant, as we aim to expose this tension and more adequately represent what was observed in terms of the complex relationships between place, authenticity, and authority.

\section{Rights or privileges; rhetoric or action}

Adventure tourists tend towards attitudes of conservation for the natural environment, observe Davidson and Stebbins (2011). The data presented here demonstrate that adventure tourism subcultures use their senses of place as emotional leverage to validate their claims of authentic practice and ethical authority in issues regarding environmental sustainability. The first examples relate to sustainability in terms of the environment overuse, stewardship, education, and responsible use - such that authenticity and ethics are suggested as practices that can be learned, taught, and disseminated to other users. 
The latter are examples of (in)equity and power that use rhetoric of authentic practice, etiquette, and rights versus privileges, thereby demonstrating the ways exclusionary politics are performed in the name of environmental sustainability.

\section{Access rights}

In conversations with lifestyle climbers in The Red, as well as on online forums such as redriverclimbing.com, the issue of access to climbing areas is frequently raised. Climbing areas form a mosaic of public and private land, with often unclear boundaries and varying access restrictions. In this region, the Red River Gorge Climbers' Coalition (RRGCC) is a particularly strong force teaming up with the national organization, Access Fund, to negotiate rights to access, as well as to purchase land for rock climbing. Through this association the Coalition has acquired two substantial properties: 750 acres formed the Pendergrass-Murray Recreational Preserve (PMRP) in 2004 and 309 acres established the Miller Fork Recreational Preserve (MFRP) in 2013. Additionally, there are many other private holdings owned by and/or open to climbers.

As a non-profit organization with over 500 members, the RRGCC has become one of the most influential voices in the community concerning responsible climbing practice, proper etiquette, and ethical and sustainable land use. Their espoused guidelines are printed in the region's guidebook (see Ellington, 2009). As a result they serve as an authoritative force when issues of conflict arise and decisions to close climbing areas must be assessed. Yet, in the closure of Roadside Crag in 2011 the Coalition had little influence, as it is part of a private land preserve. Witnessing violations against rules 
regarding new routes and fixed equipment, as well as severe degradation caused by the numbers of climbers (and their dogs) using the crag and improperly disposing of waste, the owners took swift action closing it immediately. Despite efforts by the Coalition to negotiate, as well as offering to provide restoration funds (\$5,000 grant), Roadside remained closed until March 2015. Users are now required to obtain a day permit for access. Senior land manager of the RRGCC, Mike Driskell, explains that this experience served as an example of the failure of the RRGCC, "A failure to address the impact and potential destruction of a wonderful crag. A lesson we learned from and are endeavoring to make sure never happens again." (Noble, 2014, http://www.climbing.com/climber/thementorship-gap-what-climbing-gyms-cant-teach-you/).

Since this incident, the Coalition has been inspired to act as an oversight organization, although this is in the early stages of implementation. While they have always hosted "trail days" - volunteer-based events to build and repair trail infrastructure - they are now also organizing educational workshops, such as "Train the Trainer" classes. These classes are advertised to individuals "who want to be active land stewards for the RRGCC and lead trail days, develop trail systems, and participate in the overall management of RRGCC lands" (http://rrgcc.org/upcoming-events/train-the-trainer-landstewardship-weekend/, 2015). This suggests that the Coalition is acting more towards their own goals and reputation for advocating practice than coming to terms with the issues of scale of impact and numbers of climbers, similar to the broader institutional challenges of sustainability identified by Wheeller (1993). In terms of "processes of valuation" (Bramwell \& Lane, 2008), the RRGCC has always prioritized access rights in 
its relations with the local community in The Red. They have only more recently had to address issues related to environmental sustainability and the overuse that has come with the region's tremendous popularity amongst rock climbers. So while the RRGCC was established in The Red, and many of its most active members are local resident climbers and lifestyle climbers, its membership actually spans the world allowing climbers from near and far to be a part of political action in The Red.

\section{Moral dilemmas}

Despite efforts by the RRGCC to engage more deeply with the climbing community in regards to use of climbing areas and increased numbers of climbers, the Coalition remains hesitant to appear to be "policing" activity and imposing etiquette. They remain committed to an "ethics by example" attitude, which while perhaps more diplomatic also incites frustration among and between particular subcultures, with individuals sometimes taking action into their own hands. Indeed, contestation permeates the community, with distinct patterns of dissent. Although the smallest in terms of numbers, lifestyle climbers and residential climbers are by far the most vocal when it comes to preferred etiquette and ethical climbing practice. Moreover, these two groups also frame their concerns within notions of sense of place, as the following lifestyle climber who works seasonally as a guide in The Red describes:

I take folks rock climbing in whatever capacity they want. Folks who have never seen a climbing harness before, first day out, to folks who maybe have a ton climbing experience and just would rather not deal with finding a partner, to 
everything in between - kids, church groups, scout groups, school groups, teaching climbing clinics, self rescue clinics, the whole nine-yards, whatever anybody wants to do. $[\ldots]$ This is definitely more of a means to an end for me right now. I do like some things about it, and I think it has potential to be something that I could really like. But there are moral dilemmas in it for me. At one point I was pretty sure I wanted to be a career guide. I like working with people. I like taking people climbing. I like showing people climbing. And I honestly think I do a really good job at it. But I also think climbing is being accessed by too many people, period. That doesn't make it right or wrong, I'm not making any comment on that, it's just a finite resource and there's more and more people doing it. I think the number one reason why more people are doing it is that it's more accessible. I'm definitely a big part of making climbing more accessible in the Red River Gorge. It's hypocritical, I know it, and I comment it on it on a regular basis. But right now it's the simplest way for me to make a living and stay sane. I don't mind doing it, a lot of times just have to look the other way and ignore the other side of what I know I may or may not be doing to the gorge. Then I have my ways of justifying too; saying, you know, a lot of these folks are going to get into climbing no matter what, so at least if I can see them even for a few hours, hopefully get some non-biased information across and help them be safe and contribute to the [climbing] community even, maybe, at the very least be less of a liability to the [climbing] community. So I justify it that way a lot. At the same rate, I probably take 50 kids a year rock climbing who wouldn't go rock climbing if there wasn't our guide service. (Male, late 20s, lifestyle climbing for 10 years) 
As this climber is aware that his services make the area more accessible to new climbers, an issue that he deeply laments, he also tries to reason with himself that in providing his guiding service he is also disseminating a strong ethical standard towards climbing, etiquette, and sustainability. The fact that he qualifies his information as "non-biased" hints at the tension within the climbing community. Rather than setting an example of "proper etiquette", he directly communicates with his clientele what is acceptable, and more importantly what is not. He hopes that as the numbers of leisure climbers visiting The Red continue to grow, his lessons will inspire a more careful and mindful relationship with the natural environment and will inform practices of etiquette more consistent with the climbing community's preferences. Yet, when he refers to the climbing "community", he is speaking about a particular subset of climbers (lifestyle and residential) who spend considerable time in The Red, are active in the RRGCC, and practice a strong environmental ethic with prescribed etiquette. Thus, his "non-biased" information regarding responsible use and what may be a "liability" for the climbing community has been established by a select few.

\section{A visible presence}

As the wilderness areas of the Adirondack Park and the High Peaks in particular continue to grow in popularity among hikers and backpackers, ethical behavior and respect for the wilderness landscape has become a more central issue for many repeat visitors. Indeed, organizations as well as individuals have assumed positions enabling them to speak for the wilderness and act as its protector. At the heart of their missions is the desire to foster 
more ethical, responsible use of the Adirondack landscape and to protect it from overuse and degradation resulting from increased traffic. The ADKhighpeaks Foundation, a nonprofit organization focused on preserving the Adirondack wilderness through both financial means and by "providing accurate recreation and educational information" (http://www.adkhighpeaksfoundation.org/adkhpf/about.php) is joined by other grassroots and nonprofit groups focused on protecting and preserving the sensitive Adirondack wilderness. And while there is certainly no dearth of concern and concomitant organizations and individuals striving to encourage more ethical and responsible use of the wilderness, some organizations are more visible and explicit in their mission than others. Namely, the Adirondack Mountain Club (ADK), is "dedicated to protecting wild lands and waters through environmental advocacy and trail construction and maintenance" (http://www.adk.org/page.php?pname=about-us), and serves as the sponsor of the Adirondack High Peaks Summit Stewardship Program. Its mission statement reads that the $\mathrm{ADK}$ is "dedicated to the conservation, preservation, and responsible recreational use of the New York State Forest Preserve" (http://www.adk.org/page.php?pname=about-us) through the actions of its members as well as through its Summit Steward program. The Adirondack Mountain Club (ADK) owns and maintains multiple properties including lodges, camps, cabins, and lean-tos as well as a visitor's center in the High Peaks wilderness area. It uses the proceeds from these properties to support its mission of "protecting and promoting the responsible recreational use us the New York State Forest Preserve" (http://www.adk.org/page.php?pname=lodging). The ADK also maintains the trails on its properties and provides the expertise of its Summit Stewards on nearby Peaks. Thus, 
ADK Summit Stewards maintain a visible presence in the High Peaks, and their presence and authority in the Peaks are sanctioned through the organization with which they are affiliated.

\section{Educating users}

Through their intimate knowledge and experience of the High Peaks as well as through the influence of the Adirondack Mountain Club, the Summit Stewards enjoy a more official appearance and identity as advocates of proper conduct in the Adirondacks. Connected explicitly with the High Peaks wilderness area and increasingly concerned for the sensitive alpine vegetation found at the higher elevations of the Peaks, ADK Summit Stewards are charged with educating hikers in the Peaks and promoting ethical behavior in the Adirondack landscape. They have also undergone training specific to the Adirondack environment and thus consider themselves purveyors of ethical and informed practice in this heavily traveled landscape. Their charge, however, often proves a difficult one, as not all hikers in the region adhere to the Stewards' code of ethics. As one Summit Steward lamented,

On one hand it's great that people come out here. It's like, who am I to say no, because look at me - I mean, I've benefitted so much from this place. But I'm also probably one of the few that has taken time to not only just give back but to learn just how to impact it less. I've been taking training for leave no trace and always having an interest in that. Always trying to minimize my negative impact and maximize my positive impact. I think if more people did that it wouldn't be 
such a big issue that you have thousands and thousands and thousands of people hiking these trails every year, every month. Leaving trash or even just leaving footprints. They always say take nothing but photos leave nothing but footprints, but we're leaving too many footprints now and the erosion that's happening both at the lower and higher levels of the mountain. I mean, my job stewarding is basically keeping people off the alpine vegetation and that is a huge struggle it seems like. No matter how much you say please stay on the rock only, you can say it a thousand different ways and usually, you don't try to say it forcefully obviously, you want it to be more informal and conversational, but it's really difficult to get that through to most people. I personally think that stems from the [fact that for the] vast majority of society, hiking and backpacking for them is a several times a year occasion. It's not something that they live, it's you know, the weekend warrior types, so they don't take time, they don't have passion for it, to want to learn about the fragility of the ecosystem and how to take steps to ensure that it survives. (Male Summit Steward)

For this volunteer, it is his training and attentiveness to the landscape, rooted in his intimate knowledge of the High Peaks that afford him a stronger sense of belonging. Through his "leave no trace" training and his role as wilderness protector, he feels less compunction for using and potentially impacting the environment he so loves. While he may lament the increased traffic on the trails and the negative impacts resulting from having so many tourists in the High Peaks, he also depends on these tourists for the maintenance of his own identity as wilderness protector, an identity that allows his use of 
the landscape to be a sanctioned and necessary one. Through his knowledge, experience, training, and his job stewarding, he secures not only a heightened sense of place but also a position of authority in using and protecting the landscape. As he sets himself apart from other tourists and recreationalists in the High Peaks, to whom he refers to as "weekend warrior types", the implication is that in his more ethical and responsible behavior, rooted in knowledge and love of place, is an authority and a more permissible presence in this wilderness landscape. As Wheeller (1993) suggests, his passion for saving the High Peaks ecosystem from the weight of overuse also sustains his ego.

\section{Authentic practices}

In addition to specific concerns for the sensitive High Peaks vegetation, however, is a broader, less easily defined disquiet. In the High Peaks Wilderness Area, many tourists are proud 46ers - hikers who have ascended the Adirondack's 46 peaks over 4,000 feet. Yet, individuals and groups of hikers choose to pursue this goal in different ways. Those who express the most concern over what they consider unethical behavior in the High Peaks are those who profess a deep and personal knowledge of the region and have developed a profound sense of place. For these wilderness enthusiasts, what is most disturbing is the way other hikers, given the pejorative sobriquet "Peak Baggers", approach the Peaks as items to be checked off a list, to be "done", "conquered", "bagged". This approach, they worry, leads to a lack of appreciation for other hikers, for the process of becoming a 46er, and for this sensitive landscape. Thus, there is a schism within the 46ers organization between some veteran members and some aspiring to hike all 46 peaks. Some veterans assume greater authority and senses of ownership, thereby 
deeming themselves authorities on ethical and appropriate behavior in the Peaks. Indeed, the ADK 46er mission statement reads, "As volunteers we are dedicated to environmental protection, to education for proper usage of wilderness areas, to participation in New York State Department of Environmental Conservation-approved trail projects, and to the support of initiatives within the Adirondack High Peaks region by organizations with similar goals that enhance our objectives" (http://adk46er.org/about.html). While access to the High Peaks is open to anyone who chooses to visit, a small subset of wilderness enthusiasts serve as self-appointed wilderness guardians and have tasked themselves with promoting ethical and responsible behavior in the Peaks. For one group of such hikers, concerns over what they considered unappreciative behaviors and improper practices led them to express a sense of ownership and a hesitation to "share" the Peaks with just anyone. The following exchange between two 46ers may help clarify the point.

I don't so much mind sharing it, but I only want to share it with people who appreciate it and know what it takes, or what it should take. So today we were hiking along and a woman said, to somebody else, we were just hiking by, you should go do this mountain to get that 2 nd one, that 3 rd one, that 4 th one. She was like trying to...the person said to her, what's the 4th one, and she said, I don't remember the name - it's that one that's way out there. And it just made my whole body cringe. And she said, all I have left is the Santanonis and Skylight. And I was like, you're that close to 46 and you don't know the names of all the mountains?! I'm sorry, I'm judging entirely, I'm sorry, but I was like, you don't get that close to your 46 and not know the names of the mountains you've already 
climbed! [...] So I just, I felt like a sense of ownership, of being like, that made me recoil because I think that people who get their 46 should earn it and they deserve it. They all deserve it, but you gotta know the names of the mountains you've climbed! Like there are some simple basic things. You know, you don't know why Colden's called Colden, why Marcy's called Marcy. There's so much history. And I think in order to appreciate, it's hard to share this with those who don't, who just come bolting through. And if they can do it, then good for them, but I do think there's separation between appreciating and conquering. (Female 46er 1$)$

Her friend joined her and they continued together,

Well, we don't really want them here. That's really what you want to say...the majority of people don't do Street and Nye. You know, they come in and they hike up Algonquin, they hike Marcy, the ones that are more publicized, Whiteface. (Female 46er 2)

But you don't know why, why they don't appreciate it [...] I mean, it's such an amazing feeling that you do want to share it, but with people who are close to you, but you don't necessarily want to share it with the world. Like, I want to share this with my daughter. I want her to do this. This experience, I want her to have it. But I don't necessarily want an ad to run in the ADK for this place. (Female 46er 1) 
For these 46ers, it is not so much the sensitive ecosystem or the traffic on the trails that is bothersome, but rather other hikers' (indeed, other 46ers') failures to comport themselves in a particular manner. It is their intimate knowledge of the landscape, borne of experience and attentiveness to its character and history, that provide these visitors confidence in their position of authority and in their authenticity as "real 46ers". Moreover, it is through years of developing a powerful sense of place in the High Peaks that they have come to feel a sense of ownership and protectiveness over the landscape and its identity. That their own identities are tied to this landscape heavily informs their attitudes toward it and toward those hikers they feel fail to show appropriate appreciation. As self-appointed purveyors of responsible attitudes and behavior in the High Peaks, they are motivated by a connection to the landscape central to their very senses of self. Thus, when others disrespect or degrade either the place or the process of becoming a 46er, they are simultaneously disrespecting those whose identities are firmly anchored to it. The sense of ownership and protection, then, is not only for the wilderness landscape but for their sense of self tied up in sense of place.

\section{Imposing ethics}

In the scenarios presented above, interviewees describe moral dilemmas and senses of responsibility that motivate rhetorical and illustrative practice towards other users. That is, they demonstrate and educate on what they deem to be proper behavior. Nevertheless, each also expressed feelings of frustration, futility, and even anger at the ways "other" users comport themselves in these adventure spaces. The following climber, however, has 
gone beyond such rhetorical and instructive practices to an active attempt to impose a particular ethical standard in The Red.

Beginning in the autumn of 2010, several climbers began to remove some of the semipermanent equipment from popular climbing routes. This did not prevent climbing per se but it did limit the skill level of those who could attempt such routes. It was through the work of fundraising and volunteer efforts that the Climbers' Coalition (RRGCC) and private owners installed permadraws on some routes. These are semi-permanent quickdraws (the mechanism which climbers must connect to hangers bolted in the rock so that they can then feed their rope through). They are "semi-permanent" in that while they can remain on the rock face for years, they must also be inspected and replaced at regular intervals. Further, because these pieces are already affixed to some of the bolts on particular climbing routes, their presence removes the necessity of the climber to use his/her own quickdraws. This, argue some climbers, down-grades the difficulty of the route and, moreover, removes a central component of sport climbing practice - clipping one's quickdraw to the bolt in the rock's surface. Additionally, the use of permadraws raised concerns that individuals were climbing such routes without inspecting the equipment, and subsequently, climbing on overly-worn and potentially dangerous equipment. These issues inspired several climbers to "clean" these routes of permadraws in an effort to force more responsible climbing practice. The following climber took part in this and defends his actions by bemoaning that such issues were not problems when the climbing community was smaller and the "locals" as the "authority" were more obvious. In other words, he contends that the greater numbers of visiting climbers (rock 
climbing tourists who stay for only a few days) necessitates greater symbolic action in order to establish an ethical standard. In advocating for a more transparent ethic, he is in actuality reifying the symbolic boundaries of the lifestyle climber subculture, particularly in regards to ethics and etiquette, to correspond with physical boundaries of The Red. Further, his actions challenge the RRGCC as an authoritative organization in the region, as he took action where he feels the RRGCC hesitates.

I think it's about being an ethical climber, and like, you know, being open about your ethics. [...] What's difficult is that back in the day the local climbing community was super obvious, you know what I mean. If you came here, you were exposed to the local climbing community, you were the minority, the locals were the majority. That's not that case now, hardly anywhere; it's way more, like, dissolved, it's way more diluted. Where there was two locals for every visiting climber, now there's ten visiting climbers for every local. So it's super hard to say, you know, take a view from the people who have authority. [...] I think, with like the stripping of the permadraws ... I think for me it was more of, umm ... I took those draws down, umm ... it had to do with a bunch of stuff, you know. It was basically asking people that climb at The Red to take a little bit more responsibility for themselves. [...] It's just safer, so the safety issue's one thing. The other was, it was like, hopefully, a wake up call to the climbing community, the local climbing community. We need to step it up and establish an ethic we can be proud of at The Red. [...] That was kind of an attempt, I think, of some of the local climbing community to address the obliviousness of everyone else. They don't even know 
where those [perma]draws came from, they don't care that, you know, people actually had to go up there to put them in and we have to actually inspect them, because no one else is going to change them out. I feel like it's a privilege to afford to visiting climbers, if they deserve it. (Male, late 20s, lifestyle climbing for 7 years)

In defending his actions, this climber is using his self-proclaimed "local" status as evidence for his authority to police climbing practice. His notion of "local" status is a complicated one, as a lifestyle climber he resides (i.e., parks his van) in The Red for only a few weeks to months each year. Community conformity and uniformity have decreased as the number of climbers in the area has increased, breeding frustration amongst some of the lifestyle climbers who, despite their hypermobility, consider this a "home" climbing area. This change in community dynamics, or "diluting" of "local" climbers by increased numbers of "visiting" climbers has resulted in a series of confrontations about etiquette and ethical climbing practice, which are examples of attempts by those who see themselves as "locals" to reassert authority. That this climber experiences The Red as home and that he has developed a strong sense of place means that he does in fact see visiting climbers as outsiders who should consider access to The Red as a privilege. In reasoning that access for "visiting" climbers is a privilege, he is counter asserting that he has earned the right to climb in The Red but also assess the ethical standard of climbing practice for others. The sense of responsibility he has developed for The Red not only validates his actions in asserting a particular standard, but it also works to put the blame for overuse on to "visiting" climbers. Indeed, identifying as a "local" communicates an 
authentic relationship with The Red as place, while also diffusing his potential role in the overuse of its climbing spaces.

\section{Negotiating authenticity, authority, and ethics}

For lifestyle climbers in The Red and Summit Stewards and 46ers in the Adirondacks, ongoing close interactions with the natural environment have resulted in senses of place along with feelings of ownership, pride, and responsibility for the continued use and well-being of these natural environments (see also Wattchow \& Brown, 2011). These close associations with The Red and the Adirondacks mean that performances of place are also performances of authenticity (see Knudsen \& Waade, 2010; Senda-Cook, 2012; Rickly-Boyd, 2013). As such, it is worthwhile to consider the ways place relates to enactments of authenticity, what this means for notions of authority in and responsibility to place, and how sense of place is put to use in the exclusionary politics of these adventure tourists.

The embodied nature of adventure forges deep emotional connections to place (Wattchow \& Brown, 2011). Grounding their moments of performative authenticity in The Red and the Adirondacks inspires senses of responsibility in these adventure tourists such that they are explicit about their desire to see these landscapes protected. Further, it is their close relationship with these places that affords them the perspective to see changes occurring and the consequences of overuse (see Wattchow \& Brown, 2011). So 
while the adventure tourists above do not explicitly state "authenticity" in regards to their relationships with their respective adventure places and other users, their descriptions nevertheless speak to key factors of the concept. That they deem particular behaviors appropriate identifies those who deviate as inauthentic, unappreciative, and undeserving of access. As Senda-Cook (2012, p. 142) uncovers in a similar context, practices that destroy perceived authentic experiences do so by disrupting a subtle conception of what outdoor recreation is or should be. In other words, these practices emphasize what authentic experiences are by showing what they are not. Perceptions of the authenticity of others' behaviors become particularly important ways of assessing fellow users (Senda-Cook, 2012). In their minds, the practices that users employ in these settings communicate one's relationship to place: as belonging in these landscapes or as unappreciative visitors. As the Summit Steward and 46ers quoted above explain, it is not that they wish to isolate others from experiencing the Adirondacks, but they want to see others using, and thereby experiencing, the Park in a similar way to their own ethically-inspired practice. In fact, that they can share it with others adds to their sense of collective identity, as, for example, "46ers" are exclusive in membership. The point of tension arises, however, where other users deviate from their sense of appreciation, practices of care, and mindfulness of use. As Senda-Cook (2012, p. 146) explains:

To distinguish between members and nonmembers of outdoor recreation subcultures, recreators find "right" ways of walking and authentic experiences with which to contrast practices of nonmembers. 
This demonstrates Bourdieu's (1984) theory of social distinction - that individuals wield aesthetics to communicate social capital. That each of the above quotes contains rhetorical distinctions of "us" from "them" suggests that lifestyle climbers in The Red and Summit Stewards and 46ers in the Adirondacks are using both material and performative assessments of other outdoor recreationalists as signifiers of subcultural identities. In particular, the second lifestyle climber quoted above makes a clear distinction between "local" and "visiting" climbers (and, similarly, the Summit Steward distinguishes himself from the "weekend warrior" type of hiker who visits just a few times per year). Interestingly, the moniker "local" does not signify climbers who reside in the area, as he himself as a full-time traveling climber takes on this identity as well. Rather, he is using the label of "local" to express the deep sense of place, which he also. correlates with explicit "authority" as to standards of etiquette and ethical practice. As a result, this climber felt compelled and righteous in his actions to impose a particular standard of climbing practice through altering the equipment on some routes, rather than trust in the organizational authority of the Climbers' Coalition.

In the cases presented here, social distinction also yields perceptions of hierarchy, and this hierarchy in regards to ideas about land use is communicated through rhetoric of ethics and moral superiority. For example, both the lifestyle climber explaining his "moral dilemma" and the Summit Steward describing the "struggle to protect the vegetation" speak about their positionality in disseminating "correct" information about use of natural resources in their respective destinations. Despite his trepidation about the increasing crowds and impacts on the area's natural environment, the lifestyle climber 
rationalizes his temporary employment with a guiding service that introduces new climbers to The Red by the fact that he is able to teach what he considers to be proper etiquette and use. Similarly, the Summit Steward struggles to reconcile that even with the imposition of a "leave no trace" ethic, the sheer numbers of hikers in certain areas of the Adirondacks are still too impactful in terms of erosion and trail use. So while he volunteers his time to communicate more ethical practice and sustainable use, he also hints at a degree of futility in his efforts. Thus, in each of the quotes presented above, the discussion of ethics, whether explicit or implicit, demonstrates rhetorical maneuvers aimed at drawing distinction between user groups in the face of real challenges and potential solutions. The association with more "ethical" practices, in both cases, is not solely about prioritizing access but also about substantiating the authenticity of their own experiences and minimizing their own roles in overuse. This demonstrates the necessity of examinations of sustainability to reach beyond the environmental impacts of tourists to the ways different users value the landscape and other users, as well as the discourses of power that relate to these values. In the examples presented here, overuse and/or degradation are the result of current patterns of use. As these users voice such concerns, their solutions vary from demonstrating particular behavior and educating users to chastising "unappreciative" practices and removing "privileges" of unwanted users.

\section{Conclusion}


While some studies claim the tension witnessed among adventure tourists is the result of processes of social distinction alone (see Johnson \& Edwards, 1994), this paper suggests that the processes by which individuals develop a sense of place, and the emotive power of that relationship, is equally, if not more significant (see Wattchow \& Brown, 2011). Of course, social distinction takes place and is reified through both material and rhetorical practices, but the impetus for those practices, in the case of these adventure tourists, stems more from a sense of responsibility inspired by moments of existential authenticity and deep senses of place. That this becomes a rhetorical battle over authenticity and ethics is indicative of the ways such tensions surface around practical matters of land use decisions, carrying capacity, and sustainability (see also Wheeller, 1993). While there is little doubt that lifestyle climbers in The Red and Summit Stewards and 46ers in the Adirondacks want to see greater conservation of these places, their affiliation with selfdescribed "ethical" practice reifies the authenticity of their experiences and minimizes their actions as part of the collective overuse of these natural resources.

In presenting quotes from lifestyle climbers in The Red and Summit Stewards and 46ers in the Adirondacks, we do not wish to advocate their particular environmental ethics. Rather, we have aimed to illustrate the ways different user groups assess one another's practices and pass judgment as to the right to access through the frame of authenticity and ethics. Particular practices become naturalized among adventure tourists such that deviations are deemed "inauthentic" (see Senda-Cook, 2012) and associated with a lack of ethics. In witnessing the increased degradation of The Red and the Adirondacks with growth in tourist numbers, the adventure tourists presented here are able to use their 
"authentic" practices as evidence of stronger environmental ethic, thereby assigning the burden of overuse to others. This results in further tension, as the practical matter of overuse is forced to the background while conflicts over ethics waged in the fore.

"[T]here is a hiatus in the literature between the discourses of authenticity and sustainability in tourism" (Cohen, 2002, p. 274). Sustainability is an ideological tool that can be used to empower and legitimize agents of sustainable tourism development to claim "the authority to define the criteria of sustainability" (Cohen, 2002, p. 268). In claiming and asserting authority regarding sustainability, discourses of authenticity, ethics, and place are put to use. Examining these discourses reveals complex "processes of valuation" (Bramwell \& Lane, 2008). Valuation processes inform the extent to which these adventure tourists take responsibility for the natural environment. As a space in which they perform adventure, they value the natural environment as a means to adventure. Their emotional attachments to such spaces are a result of the embodied adventure experiences within them (Wattchow \& Brown, 2011). Valuation processes also inform, then, perceptions of responsible use, environmental ethics, and authentic practices by other users. While companion users are a key component of most adventure experiences, all users are not valued equally. Thus, notions of ethical authority regarding sustainability stem from responsibility to place but are also put to use as valuation processes in the form of authenticity rhetoric towards other users. 


\section{References}

Agyeman, J. \& Evans, B. (2004) 'Just sustainability': The emerging discourse of environmental justice in Britain? The Geographical Journal. 170, 155-164.

Adirondack 46ers (2015). Retrieved from: http://adk46er.org. Last accessed August 28, 2015.

Adirondack Mountain Club (2015). Retrieved from http://www.adk.org/page.php?pname=about-us. Last accessed September 18, 2015. Adirondack Mountain Club (2015). Retrieved from http://www.adk.org/page.php?pname=lodging. Last accessed September 21, 2015.

ADKhighpeaks Foundation (2015). Retrieved from http://www.adkhighpeaksfoundation.org/adkhpf/about.php. Last accessed September 21, 2015.

Beedie, P. (2003). Mountain guiding and adventure tourism: reflections on the choreography of the experience. Leisure Studies, 22, 147-167.

Beedie, P. (2008). Adventure tourism as a "new frontier" in leisure. World Leisure Journal, $50,173-183$.

Beedie, P. \& Hudson, S. (2003). Emergence of mountain-based adventure tourism. Annals of Tourism Research, 30, 625-643.

Belhassen, Y., Caton, K., \& Stewart, W.P. (2008). The search for authenticity in the pilgrim experience. Annals of Tourism Research, 35, 668-689.

Bourdieu, P. (1984). Distinction: A social critique of the judgment of taste. Cambridge, MA: Harvard University Press.

Bramwell, B. \& Lane, B. (2008) Editorial: Priorities in sustainable tourism research. 
Journal of Sustainable Tourism, 16, 1-4.

Braun, B. (2002). The intemperate rainforest: Nature, culture, and power on Canada's west coast. Minneapolis, MN: University of Minnesota Press.

Christensen, D. (1990). Adventure tourism. In J. Miles \& S. Priest (Eds.), Adventure education (433-441). State College, PA: Venture Publishing.

Cloke, P. \& Perkins, H.C. (1998). "Cracking the canyon with the awesome foursome": representations of adventure in New Zealand. Environment and Planning D: Society and Space, 16, $185-218$.

Cloke, P. \& Perkins, H.C. (2002). Commodification and adventure in New Zealand tourism. Current Issues in Tourism, 5, 521-549.

Cohen, E. (2002) Authenticity, equity and sustainability in tourism Journal of Sustainable Tourism, 10, 267-276.

Costa, C. A. \& Chaiip, L. (2005). Adventure sport tourism in rural revitalisation - an ethnographic evaluation. European Sport Management Quarterly, 5, 257-279.

Csikszentmihalyi, M. \& Selega, I. (1990). Adventure and the flow experience. In J. Miles \& S. Priest (Eds.), Adventure education, (149-155). State College, PA: Venture Publishing.

Davidson, L. \& Stebbins, R. A. (2011). Serious leisure and nature: Sustainable consumption in the outdoors. Basingstoke, Hampshire: Palgrave Macmillan.

Driskell, M. (2015). Train the trainer, land stewardship weekend. Retrieved from: http://rrgcc.org/upcoming-events/train-the-trainer-land-stewardship-weekend/ Last accessed 13 September 2015.

Ellington, R. (2009). Red River Gorge rock climbs. Silt, CO: Wolverine Publishing. 
Erikson, B. (2005). Style matters: explorations of bodies, whiteness, and identity in rock climbing. Sociology of Sport Journal, 22, 373-396.

Ewert, A. (1985). Why people climb: the relationship of participant motives and experience to mountaineering. Journal of Leisure Research, 17, 241-250.

--- (1993). Differences in the level of motive importance based on trip outcome, experience level, and group type. Journal of Leisure Research, 25, 335-349.

Ewert, A. \& Hollenhorst, S. (1989). Testing the adventure model: empirical support for a model of risk recreation participation. Journal of Leisure Research, 21, 124-139.

Ewert, A. \& Hollenhorst, S. (1994) Individual and setting attributes of the adventure recreation experience. Leisure Sciences, 16, 177-191.

Fennell, D. A. \& Eagles, P.F.J. (1990). Ecotourism in Costa Rica: a conceptual framework. Journal of Park and Recreation Administration, 8, 23-34.

Fletcher, R. (2014). Romancing the wild: cultural dimensions of ecotourism. Durham, NC: Duke University Press.

Hall, C. M. (1992). Adventure, sport and health tourism. In B. Weiler \& C. M. Hall (Eds.), Special interest tourism (141-158). London: Belhaven.

Heywood, I. (1994). Urgent dreams: climbing, rationalization and ambivalence. Leisure Studies, 13, 179-194.

Johnson, B. \& Edwards, T. (1994). The commodification of mountaineering. Annals of Tourism Research, 21, 459-478.

Kane, M. J. \& Tucker, H. (2004). Adventure tourism: the freedom to play with reality. Tourist Studies, 4, 217-234.

Kane, M. J. \& Zinc, R. (2004). Package adventure tours: markers in serious leisure. 
Leisure Studies, 23, 329-345.

Kiewa, J. (2002). Traditional climbing: metaphor of resistance or metanarrative of oppression? Leisure Studies, 21, 134-161.

Knudsen, B. T. \& Waade, A.M. (2010). Performative authenticity in tourism and spatial experience: rethinking the relations between travel, place and emotion. In B. T. Knudsen \& A. M. Waade (Eds.), Re-Investing authenticity: Tourism, place and emotions (1-21). Bristol: Channel View Publications.

Lewis, N. (2004). Sustainable adventure: embodied experiences and ecological practices within British climbing. In B. Wheaton (Ed.), Understanding lifestyle sports: consumption, identity and difference (70-93). London: Routledge.

Mowforth, M. \& Munt, I. (2003). Tourism and sustainability: Development and new tourism in the third world. London: Routledge.

Noble, C. (2014). The mentorship gap: what climbing gyms can't teach you. Climbing. http://www.climbing.com/climber/the-mentorship-gap-what-climbing-gyms-cantteach-you/ Last accessed 13 September 2015.

Palmer, C. (2002). 'Shit Happens': the selling of risk in extreme sport. The Australian Journal of Anthropology, 12, 323-336.

Price, T. (1978). Adventure by numbers. In K. Wilson (Ed.), The games climbers play (646-651). London: Diadem.

Priest, S. (1990). The adventure experience paradigm. In J. Miles \& S. Priest (Eds.), Adventure education (157-162). State College, PA: Venture Publishing.

Priest, S. (1992). Factor exploration and confirmation for the dimensions of an adventure experience. Journal of Leisure Research, 24, 127-139. 
Rickly-Boyd, J. M. (2012a) Authenticity \& Aura: A Benjaminian Approach to Tourism. Annals of Tourism Research, 39(1), 269-289.

--- (2012b) Lifestyle Climbers: Towards Existential Authenticity. Journal of Sport \& Tourism, 17(2), 85-104.

--- (2013) Existential Authenticity: Place Matters. Tourism Geographies, 15(4), 680686.

Rubens, D. (1999). Effort or performance: keys to motivated learners in the outdoors. Horizons, 4, 26-28.

Scott, D. (1994). Trekking commentary. High 134, 56-59.

Senda-Cook, S. (2012). Rugged practices: embodying authenticity in outdoor recreation. Quarterly Journal of Speech, 98, 129-152.

Sung, H., Morrison, A., \& O'Leary, J. (2000). Segmenting the adventure travel market by activities: from the North American industry provider's perspective. Journal of Travel and Tourism Marketing, 9, 1-20.

Varley, P. (2006). Confecting adventure and playing with meaning: the adventure commodification continuum. Journal of Sport and Tourism, 11, 173-194.

Varley, P. (2011). Sea kayakers at the margins: the liminoid character of contemporary adventures. Leisure Studies, 30, 85-98.

Vidon, E. (2015). Co-constructing the wild: Adirondack wilderness and the "nature tourist" (Unpublished doctoral dissertation). Indiana University, Bloomington, IN.

--- (2016). The call of the wild: Power and ideology in the Adirondack Park. In S. Nepal \& J. Saarinen (Eds.), Political ecology and tourism (100-114). New York: Routledge. 
Wang, N. (1999). Rethinking authenticity in tourism experience. Annals of Tourism Research, 26, 349-370.

Wattchow, B., \& Brown, M. (2011). Pedagogy of place: Outdoor education for a changing world. Melbourne: Monash University Publishing

Weber, K. (2001). Outdoor adventure tourism: a review of research approaches. Annals of Tourism Research, 28, 360-377.

Wheaton, B. (2004). Introduction: Mapping the Lifestyle Sport-Scape. In B. Wheaton (Ed.), Understanding lifestyle sports: Consumption, identity and difference (1-28). London, Routledge.

Wheaton, B. (2007). After sport culture: rethinking sport and post-subcultural theory. Journal of Sport and Social Issues, 22(2), 283-307.

Wheaton, B. \& Beal, B. (2003). "Keeping it Real": subcultural media and the discourses of authenticity in alternative sport. International Review for the Sociology of Sport, 38(2), 155-176.

Wheeller, B. (1993) Sustaining the ego. Journal of Sustainable Tourism, 1(2), 121-129.

Williams, T. \& Donnelly, P. (1985). Subcultural production, reproduction, and transformation in climbing. International Review for the Sociology of Sport, 20, 317.

\section{Acknowledgements}

Jillian Rickly would like to acknowledge the Dissertation Year Fellowship from Indiana University that helped to fund the research with climbers in the Red River Gorge. 
Elizabeth Vidon would like to acknowledge the Adirondack Mountain Club (ADK) and SUNY-ESF's Adirondack Ecological Center and Adirondack Interpretive Center for their support and assistance during field study in the Adirondack Park.

A draft of this paper was presented at the Nordic Symposium in Tourism and Hospitality in Iceland (2015). The audience comments were much appreciated and contributed to our development of the theoretical ideas presented in this final version. The authors wish to also thank the anonymous reviewers for their constructive critiques. This feedback most certainly improved the paper. With that said, any remaining errors are the sole responsibility of the authors.

\footnotetext{
${ }^{1}$ Sport climbing is a type of free climbing, which opposed to aid climbing that uses devices to ascend a rock face, uses only the body to move along the rock's surface. Equipment is still a necessary part of sport climbing, but it is used for safety in the case of a fall. Sport climbing employs permanent bolts in the rock that hold a hanger to which the climber clips one carabineer end of a quickdraw while threading a rope through the carabineer at the other end. Thus, sport climbing differs from its predecessor, traditional climbing, through the use of permanent bolts, rather than nuts and cams, which are temporary protective gear placed it rock features, mainly cracks.
} 